\title{
Capturing patients' experiences to change Parkinson's disease care delivery: a multicenter study
}

\author{
Martijn van der Eijk ${ }^{1} \cdot$ Marjan J. Faber ${ }^{1,2} \cdot$ Bart Post $^{3} \cdot$ Michael S. Okun ${ }^{4} \cdot$ \\ Peter Schmidt $^{5} \cdot$ Marten Munneke $^{2,3} \cdot$ Bastiaan R. Bloem $^{3}$
}

Received: 14 May 2015/Revised: 31 July 2015 / Accepted: 1 August 2015/Published online: 21 August 2015

(C) The Author(s) 2015. This article is published with open access at Springerlink.com

\begin{abstract}
Capturing patients' perspectives has become an essential part of a quality of care assessment. The patient centeredness questionnaire for PD (PCQ-PD) has been validated in The Netherlands as an instrument to measure patients' experiences. This study aims to assess the level of patient centeredness in North American Parkinson centers and to demonstrate the PCQ-PD's potential as a quality improvement instrument. 20 Parkinson Centers of Excellence participated in a multicenter study. Each center asked 50 consecutive patients to complete the questionnaire. Data analyses included calculating case mix-adjusted scores for overall patient centeredness (scoring range 0-3), six
\end{abstract}

For the Patient centeredness study group (see Acknowledgements).

Electronic supplementary material The online version of this article (doi:10.1007/s00415-015-7877-2) contains supplementary material, which is available to authorized users.

Martijn van der Eijk

martijn.vandereijk@radboudumc.nl

Bastiaan R. Bloem

bas.bloem@radboudumc.nl

1 Department of Neurology, Radboud Institute of Health Sciences (RIHS), Radboud University Medical Center, Nijmegen, The Netherlands

2 Scientific Institute for Quality of Healthcare (IQ Healthcare), Radboud University Medical Center, Nijmegen, The Netherlands

3 Department of Neurology (935), Donders Institute for Brain, Cognition and Behaviour, Radboud University Medical Center, Nijmegen, The Netherlands

4 McKnight Brain Institute, UF Health College of Medicine, University of Florida Center for Movement Disorders and Neurorestoration, Gainesville, FL, USA

5 National Parkinson Foundation, Miami, FL, USA subscales (0-3), and quality improvement (0-9). Each center received a feedback report on their performance. The PCQ-PD was completed by 972 PD patients (median 50 per center, range 37-58). Significant differences between centers were found for all subscales, except for emotional support $(p<0.05)$. The information subscale (mean 1.62 SD 0.62) and collaboration subscale (mean $2.03 \mathrm{SD} 0.58)$ received the lowest experience ratings. 14 centers $(88 \%)$ who returned the evaluation survey claimed that patient experience scores could help to improve the quality of care. Nine centers (56\%) utilized the feedback to change specific elements of their care delivery process. PD patients are under-informed about critical care issues and experience a lack of collaboration between healthcare professionals. Feedback on patients' experiences facilitated Parkinson centers to improve their delivery of care. These findings create a basis for collecting patients' experiences in a repetitive fashion, intertwined with existing quality of care registries.

Keywords Parkinson's disease · Patient experiences · Quality of life - Outcome research · Patient-centered care

\section{Introduction}

In 2001, the National Academy of Medicine introduced six areas to improve the quality of the US healthcare system. These areas were built around the fundamental needs for healthcare, which has to be safe, effective, equitable, timely, efficient, and patient centered [1]. Patient centeredness is increasingly recognized as a critical aspect and deficiency in care delivery [1-3]. The concept can be defined as providing care that is respectful of and 
Table 1 PCQ-PD care aspects

\begin{tabular}{|c|c|}
\hline Subscales & Care aspects \\
\hline Information 12 items & $\begin{array}{l}\text { Patient organizations (Q1), adaptive equipment, home care and facilities (Q2), reliable information (Q3), peer support } \\
\text { (Q4), medication use and side effects (Q5), reimbursement of treatment costs (Q6), contact after medication regimen } \\
\text { changes (Q7), alternative health therapies (Q8), advanced treatment options (Q9), ability to drive a car (Q10), find } \\
\text { health professionals specialized in PD (Q11), and treatment options allied health professionals (Q12) }\end{array}$ \\
\hline Collaboration 11 items & $\begin{array}{l}\text { Leading physician (Q13), care coordinator (Q14), awareness of professionals of each other's involvement (Q15), } \\
\text { mutual agreements (Q16), conflicting information (Q17), informed about what professionals discussed regarding } \\
\text { your treatment (Q18), cooperation second opinion (Q19), timely referrals (20), collaboration PD nurse specialist and } \\
\text { neurologist (Q21), collaboration between physicians (Q22), and fixed contact for questions or complaints (Q25) }\end{array}$ \\
\hline Accessibility 4 items & $\begin{array}{l}\text { Waiting period before visiting a neurologist (Q23), waiting period in waiting room (Q24), email access (Q26), and } \\
\text { telephone access (Q27) }\end{array}$ \\
\hline Empathy 5 items & $\begin{array}{l}\text { Questions answered in a timely manner (Q28), listen carefully (Q29), take enough time (Q30), explain things clearly } \\
\text { (Q31), and professional competence (Q32) }\end{array}$ \\
\hline $\begin{array}{l}\text { Patient involvement } 6 \\
\text { items }\end{array}$ & $\begin{array}{l}\text { Access to medical record (Q33), authorize who has access to your medical record (Q34), opportunity to choose your } \\
\text { health professional (Q35), opportunity to schedule appointments (Q36), adapt treatment to personal preferences } \\
\text { (Q37), and participation in treatment decisions (Q38) }\end{array}$ \\
\hline $\begin{array}{l}\text { Emotional support } 6 \\
\text { items }\end{array}$ & $\begin{array}{l}\text { Attention paid to the caregiver (Q39), active involvement of the caregiver (Q40), support after the diagnosis was first } \\
\text { communicated (Q41), support coping with the disease (Q42), support relationship changes (Q43), and support related } \\
\text { to employment (Q44) }\end{array}$ \\
\hline
\end{tabular}

responsive to individual preferences, and ensuring that the patient's needs guide all clinical decisions.

Patient-centered care reflects an ethical norm inherent to medicine [4]. In addition to the intrinsic value, the approach is associated with improved physical and psychosocial health outcomes [5-7]. Moreover, patient centeredness increases treatment adherence among chronically ill patients [8]. The concept may lower costs by a shortened length of stay in the hospital, decreased adverse events, and reduced healthcare utilization [9-11].

To integrate the concept into a comprehensive assessment of quality of care, we need validated instruments and an assessment of current levels of patient centeredness [12]. Increasingly, experience questionnaires have been recognized to provide insight into the level of patient centeredness [13, 14]. Moreover, improving care experiences have become a key priority for health system reform in the US [15, 16]. The Affordable Care Act mandated new payment approaches based in part on the results of patient experience surveys [17].

The US and England have the longest tradition of measuring care experiences, through the Consumer Assessment of Healthcare Providers and Systems (CAPHS) questionnaire (US) and the Picker Institute survey (used by the NHS). The patient centeredness questionnaire for PD (PCQ-PD) has been developed according to Dutch standards for measuring patients' experiences [18]. This study aimed to validate the PCQPD for use in US-based populations, to assess the level of patient centeredness in North American Parkinson centers, and also to demonstrate the PCQ-PD's potential as a quality improvement instrument.

\section{Methods}

\section{Cross-cultural validation}

A cross-cultural validation procedure was applied to the Dutch version of the PCQ-PD to test the applicability in National Parkinson Foundation (NPF) centers in the US and Canada [19]. Cross-cultural validation included a translation of the questionnaire from Dutch into English, based on a forward-backward translation process by two researchers and a bilingual translator, online expert consultation with 17 movement disorders specialists and pre-testing the face and content validity by conducting 15 cognitive interviews with health professionals, patients, and caregivers in the UF Center for Movement Disorders and Neurorestoration. Consequently, some items were refined, for example, the word 'tools' was changed into 'adaptive equipment' (Q2) and 'complementary medicine' into 'alternative health therapies'(Q8). Two new items were included (Q4-Q28), and one item was removed. 'When to start with medication' referred to the right time to take anti-Parkinson medication; immediately after the diagnosis or during the course of the disease. All American interviewees started immediately. The PCQ-PD consists of 15 items on patient characteristics, e.g., gender, age, race, and health 
status and 44 care aspects covering six subscales of patient centeredness (Table 1 and electronic supplementary material).

\section{Multicenter study}

\section{Data collection}

North American NPF centers were invited to participate in a multicenter study $(n=48)$. These centers are recognized as leaders in Parkinson care based on their ongoing research, comprehensive care delivery, and professional education. In each participating center, a research coordinator was assigned to distribute the PCQ-PD. Patients with idiopathic PD, multiple system atrophy, or progressive supranuclear palsy were included. Patients diagnosed with severe cognitive impairment, like Lewy body disease, corticobasal degenerative disease, Parkinson's disease dementia, or MMSE <24 were excluded.

Consecutive patients were asked to complete the questionnaire at the clinical site after their consultation with a neurologist. The PCQ-PD was accompanied by an informed consent form, a return envelope, and a cover letter signed by local neurologists. Neither patient names nor addresses were stated. The PCQ-PD had a center identification number only. Completed questionnaires were stored in a sealed envelope and returned to the research coordinator. All centers applied for ethical approval by a local institutional review board. The protocol was exempted from review, since patients could not be identified from the data and the study did not involve an intervention, specimens, or devices.

\section{Sample size calculation}

The PCQ-PD's ability to discriminate between practices can be determined by the Intra-class Correlation Coefficient (ICC) [20]. The ICC accounts for the relatedness of clustered data (here: patients clustered in Parkinson centers) by comparing the variance within centers with the variance between centers. High ICC values indicate greater variation between centers, relative to variation within centers. Sample size calculations showed that with 20 participating centers, an estimated ICC of $5 \%$ (95\% CI 0.01-0.14), 50 patients had to complete the PCQ-PD per center [21].

\section{Data processing}

Completed questionnaires were processed manually, and data were entered into SPSS. Systematic and random errors were detected and instantly corrected by conducting frequency analyses and by entering the data of $5 \%$ of the questionnaires twice $(n=50)$. Participants completing $<50 \%$ of the experience items were excluded. Three items were negatively phrased (Q17-23-24). Thus, a positive answer indicated a negative experience on this aspect. Data of these items were mirrored, allowing for comparison with other items where higher scores indicated better experiences.

\section{Data analysis}

For each item an Item Experience Score (IES) $(0=$ No, not at all, $1=$ Yes, to some extent, $2=$ Yes, to a moderate extent, and $3=$ Yes, to a great extent), an Item Priority Score (IPS), $(0=$ Not important, $1=$ Fairly important, $2=$ Important, and $3=$ Extremely important), a proportion of negative experiences (\% respondents with IES 0 or 1), and a Quality Improvement Score (QIS) were calculated at the center level. The latter represents those care aspects where patients report negative experiences in combination with high priorities and can as such be labeled as having priority for quality improvement. QIS was calculated by the maximum IES of 3 minus the observed IES, multiplied by the observed IPS. Consequently, improvement scores vary from 0 to 9 ; the higher the score, the higher the need for improvement. For each center, case mix-adjusted subscale scores (0-3) and an Overall Patient centeredness Score (OPS) (0-3) were calculated using a general linear model. To determine any differences between centers, oneway ANOVA analysis was performed.

\section{Discriminative power}

Multivariate multilevel regression analysis was performed to assess the discriminative power of the PCQ-PD between centers [22, 23]. First, univariate multilevel regression analyses were performed between patient characteristics and subscale scores. Next, two nested models were fitted to the data. The first model was a random-intercept model without explanatory variables (0-model). The second model was performed with patient characteristics as fixed effects (1-model). Casemix adjusters with a $p$ value $<0.20$ in the univariate regression analysis were included in the multivariate regression model using a backward selection procedure [24]. Discriminative power was determined by calculating ICCs for each subscale in both the 0 and 1 model, with a random intercept at the center level. To assess how much variance in each 0 -model is attributable to differences in patient characteristics, the proportional change in variance was calculated [25].

\section{Feedback reports}

Each center received a feedback report on their level of patient centeredness. The report included an Overall 
Table 2 Patient characteristics

\begin{tabular}{|c|c|c|}
\hline Net response & $N$ & 955 \\
\hline Respondents per center & Median (range) & $50(37-58)$ \\
\hline Age (years) & Median (range) & $69.0(32-93)$ \\
\hline Gender & $n(\%)$ women & $377(38.8)$ \\
\hline \multirow[t]{5}{*}{ Level of education } & $n(\%)$ college or university degree & $501(52.5)$ \\
\hline & $n(\%)$ technical or community college & $75(7.9)$ \\
\hline & $n(\%)$ college no degree & $157(16.5)$ \\
\hline & $n(\%)$ high school & $170(17.8)$ \\
\hline & $n(\%)$ less than high school & $51(5.3)$ \\
\hline \multirow[t]{2}{*}{ Diagnosis } & Parkinson's disease & $928(97.2)$ \\
\hline & Parkinsonism (MSA and PSP) & $27(2.8)$ \\
\hline Disease duration (years) & Median (range) & $7.0(1-40)$ \\
\hline \multirow[t]{5}{*}{ Self-reported Hoehn and Yahr disease stage } & $n(\%) \mathrm{HY} 1$ & $306(32.5)$ \\
\hline & $n(\%) \mathrm{HY} 2$ & $190(20.2)$ \\
\hline & $n(\%) \mathrm{HY} 3$ & $374(39.7)$ \\
\hline & $n(\%) \mathrm{HY} 4$ & $49(5.2)$ \\
\hline & $n(\%)$ HY5 & $22(2.3)$ \\
\hline \multirow[t]{5}{*}{ Self-reported physical health status } & $n(\%)$ excellent & $70(7.4)$ \\
\hline & $n(\%)$ very good & $301(31.6)$ \\
\hline & $n(\%)$ good & $387(40.7)$ \\
\hline & $n(\%)$ fair & $165(17.3)$ \\
\hline & $n(\%)$ poor & $29(3.0)$ \\
\hline \multirow[t]{5}{*}{ Self-reported mental health status } & $n(\%)$ excellent & $155(16.3)$ \\
\hline & $n(\%)$ very good & $363(38.1)$ \\
\hline & $n(\%)$ good & $298(31.3)$ \\
\hline & $n(\%)$ fair & $116(12.2)$ \\
\hline & $n(\%)$ poor & $20(2.1)$ \\
\hline \multirow[t]{5}{*}{ Race } & $n(\%)$ Caucasian & $671(93.6)$ \\
\hline & $n(\%)$ African American & $17(2.4)$ \\
\hline & $n(\%)$ Asian & $14(2.0)$ \\
\hline & $n(\%)$ American Indian or Alaska native & $2(0.3)$ \\
\hline & $n(\%)$ other & $13(1.8)$ \\
\hline \multirow[t]{5}{*}{ Overall quality of care } & $n(\%)$ excellent & $603(62.6)$ \\
\hline & $n(\%)$ very good & $265(27.5)$ \\
\hline & $n(\%)$ good & $77(8.0)$ \\
\hline & $n(\%)$ fair & 15 (1.6) \\
\hline & $n(\%)$ poor & $3(0.3)$ \\
\hline
\end{tabular}

Patient centeredness Score (OPS) and subscale scores anonymously benchmarked against other centers. Additionally, Quality Improvement Scores (QIS) and patients' qualitative feedback were presented. Hereby, health professionals could identify care aspects with the highest priority for improvement in their own center. Professionals were encouraged to discuss the report within their medical team but were free to change aspects of care that needed improvement according to their patients. After 3 months, medical directors and research coordinators received a survey to evaluate the impact of the feedback report.

\section{Results}

\section{Respondents}

20 Parkinson Centers of Excellence participated in this study (center participation rate $41.7 \%$ ). The PCQ-PD was completed by 972 PD patients (median 50 per center, range 37-58). 17 patients were excluded based on having another diagnosis, and this included depression, essential tremor, dementia, or dystonia $(n=7)$, or because of completing $<50 \%$ of the experience items $(n=10)$. Patient characteristics of all respondents are shown in Table 2. 
Fig. 1 Level of patient centeredness in North American Centers of Excellence. The dots and boxes in Fig. 1 represent casemix-adjusted mean scores per subscale for each center. The horizontal lines in each boxplot represent the minimum, first quartile, median, third quartile, and maximum score per subscale. Dots plotted outside the boxplot are outliers. The OPS and subscale scores for the total study population are presented below Fig. 1

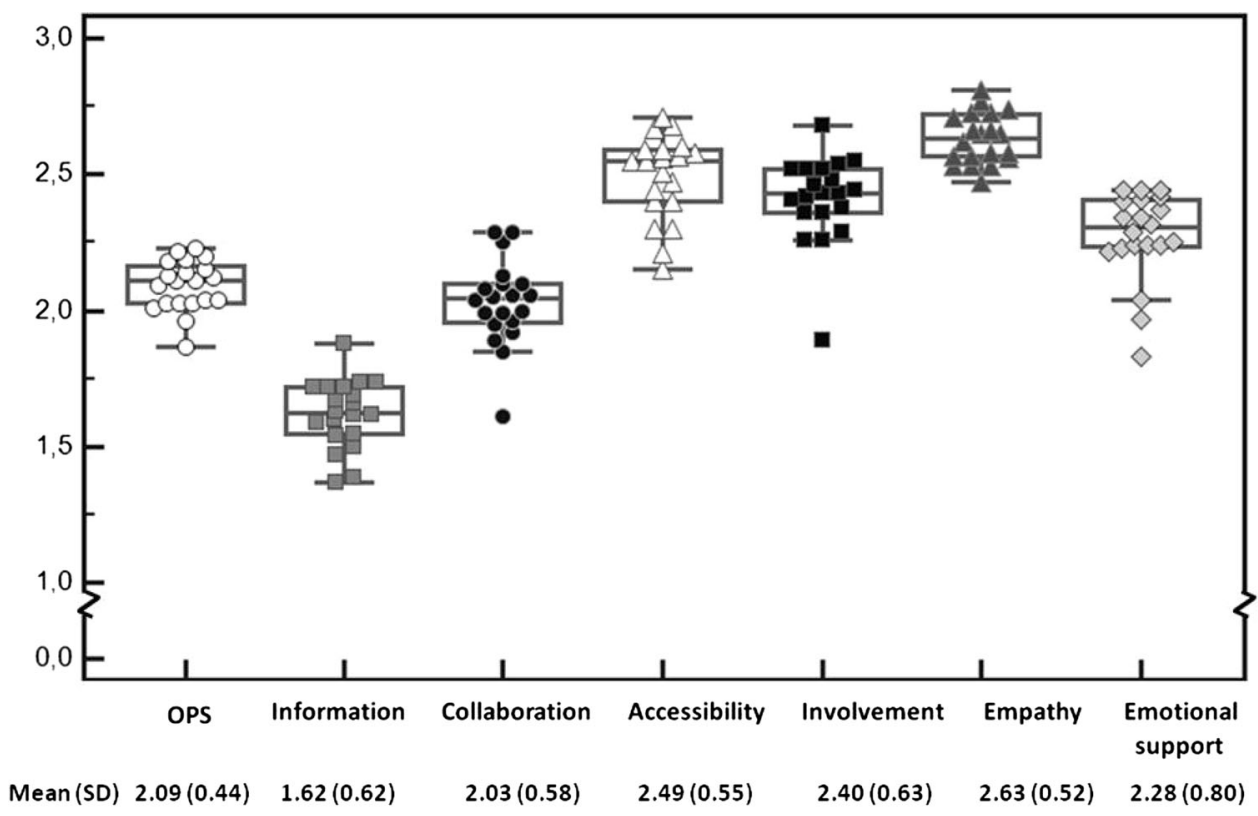

Table 3 Quality Improvement Scores

\begin{tabular}{|c|c|c|c|c|c|c|}
\hline Item & & Subscale & $\% \mathrm{NE}$ & $\begin{array}{l}\text { IES } \\
(0-3)\end{array}$ & $\begin{array}{l}\text { IPS } \\
(0-3)\end{array}$ & $\begin{array}{l}\text { QIS } \\
(0-3)\end{array}$ \\
\hline Q18 & $\begin{array}{l}\text { Informed about what professionals discussed with each other regarding your } \\
\text { treatment }\end{array}$ & Collaboration & 80.3 & 0.80 & 2.19 & 4.80 \\
\hline Q8 & Informed about alternative health therapies & Information & 71.0 & 1.03 & 2.07 & 4.08 \\
\hline Q7 & Being contacted after a new medication regimen & Information & 61.1 & 1.22 & 2.21 & 3.94 \\
\hline Q9 & Informed about advanced treatment options & Information & 62.6 & 1.33 & 2.24 & 3.73 \\
\hline Q16 & Mutual agreements about your treatment & Collaboration & 60.9 & 1.30 & 2.16 & 3.68 \\
\hline Q2 & Informed about adaptive equipment, home care and facilities & Information & 73.5 & 1.03 & 1.72 & 3.39 \\
\hline Q1 & Informed about Parkinson's disease patient organizations & Information & 75.3 & 0.95 & 1.55 & 3.17 \\
\hline Q22 & Collaboration between physicians & Collaboration & 46.7 & 1.73 & 2.39 & 3.05 \\
\hline Q10 & Informed about ability to drive a car & Information & 50.1 & 1.61 & 2.10 & 2.93 \\
\hline Q12 & Informed about treatment options allied health professionals & Information & 41.8 & 1.80 & 2.44 & 2.92 \\
\hline
\end{tabular}

$\% N E$ the proportion of patients with a negative experience with that aspect, IES Item Experience Score, IPS Item Priority Score, QIS Quality Improvement Score $=(3-$ IES $) \times$ IPS

\section{Overall patient centeredness and subscale scores}

The information subscale [mean 1.62 (SD 0.62)] and collaboration subscale [mean 2.03 (SD 0.58)] received the lowest experience ratings. Accessibility of care [mean 2.49 (SD 0.55)] and empathy [mean 2.63 (SD 0.52)] received the highest experience ratings. The Overall Patient centeredness Score (OPS) and casemix-adjusted subscale scores for each center are shown in Fig. 1. OPS ranged from 1.87 (95\% CI 1.74-2.00) for the worst performing center to $2.23(2.11-2.36)$ for the best $(\delta 0.36)$. Subscale scores ranged from 1.89 to $2.68(\delta 0.79)$ for patient involvement; $1.61-2.29 \quad(\delta$ 0.68) for collaboration;
1.83-2.44 $(\delta 0.61)$ for emotional support; $2.15-2.71(\delta$ $0.56)$ for accessibility; $1.37-1.88(\delta 0.51)$ for information; and 2.47-2.81 ( $\delta 0.34)$ for empathy.

\section{Quality Improvement Scores(QIS)}

The item with the highest QIS 4.80 was 'Were you informed about what your health professionals discussed with each other regarding your treatment?'(Table 3). $80.3 \%$ of the respondents indicated to have a negative experience on this item. Care aspects with the highest potential for improvement are all information and collaboration subscale items. Care aspects with the highest 
priority scores were all empathy subscale items. However, these items had low QIS, as patients experience good care on these aspects.

\section{Evaluation of the feedback reports}

Eight medical directors and 12 research coordinators representing 16 centers $(80 \%)$ returned the evaluation survey. All respondents read the report and all but two discussed the report within their medical team. Moreover, nine centers $(56 \%)$ shared the results with patients in the waiting room. The feedback report was perceived as a useful tool for internal quality improvement by 14 centers $(88 \%)$. Respondents stated that the report easily identified areas to work on and revealed invaluable information from the patient's perspective. Additionally, nine centers (56\%) used the feedback to change specific elements within their care delivery process illustrated by the following statements: "We altered the pre-appointment checklist to ask patients to provide more input into their care (\#3); We took the top five items cited for improvement and are digging down into them more. We started a project that will allow for better driver screening (\#11); We developed a center information sheet to new patients that provides explicit information about available resources (\#13). Patients are given an email to contact the physician after 2-3 weeks in the medications changes (\#14).We have changed the way we are addressing the waiting list (\#17) and; We have added additional providers to increase accessibility and are increasing the referrals in the patient's area of residence (\#26).”

\section{Discriminative power of the PCQ-PD}

One-way ANOVA analysis showed significant differences between centers on overall patient centeredness and all subscales, except for emotional support $(p<0.05)$. Table 4 demonstrates the multilevel analysis results. Regression coefficients (column 3-9) show that gender, level of education, physical and mental health status, disease stage, language, and race are significantly related to patient centeredness scores. For example, a higher level of education is associated with more positive experiences toward information, patient involvement, and empathy. Conversely, women perceived less access to healthcare compared to men. The proportional change in variance shows that patient characteristics explain $0.7 \%$ for emotional support to $11.8 \%$ for information of the total variance detected in the 0 models. ICC values demonstrate that differences between centers were accountable for 1-6\% of the variance in patient centeredness.

\section{Discussion}

\section{Main results}

Application of the PCQ-PD in a large cohort showed that North American PD patients are under-informed about critical care issues and experience a lack of collaboration between members of their healthcare team. Moreover, significant differences in patient centeredness between the participating centers were found. Feedback on patients' experiences stimulated half of the centers to change the delivery of care at their individual center. Here, we will discuss the potential significance of these findings.

This study showed that PD patients are under-informed about critical aspects of their care, as was found previously $[18,26,27]$. A qualitative study from New Zealand on unmet needs showed that PD patients wanted their physicians to offer more information about their condition [26]. Moreover, a British study demonstrated that PD patients were poorly informed about medication and treatment options [27]. Application of the PCQ-PD in a large Dutch sample certified that patients were in need for information regarding alternative health therapies and treatment options of allied health professionals [18]. These findings reflect the complexity of providing the right information to the right person at the right time. Considerable individual differences in information needs exist, while each disease stage induces new information requirements [28]. Stratification of patients' needs by disease stage and online-personalized information might facilitate healthcare providers to target information to patient subgroups [29].

PD patients were not aware of mutual consultation and sound agreements between members of their healthcare team. Moreover, patients were not informed about what health professionals discussed with each other regarding their treatment. Two previous studies confirm that Dutch patients experience a lack of collaboration between professionals in the exact same way $[18,30]$. An integrated approach including the patient as part of the team is thought to be the best way to manage PD [31]. However, evidence quantifying positive and sustained effects of such an approach remains inconclusive [31, 32]. Novel care models, fostering the interaction between healthcare providers and patients and online exchange of medical data, may facilitate multidisciplinary collaboration in healthcare [29].

Feedback on patients' experiences stimulated health professionals to improve the delivery of care at their individual center. Three months after receiving the report, half of the centers had changed specific elements of their care delivery process. However, feedback did not encourage all centers to improve; some centers discussed the 


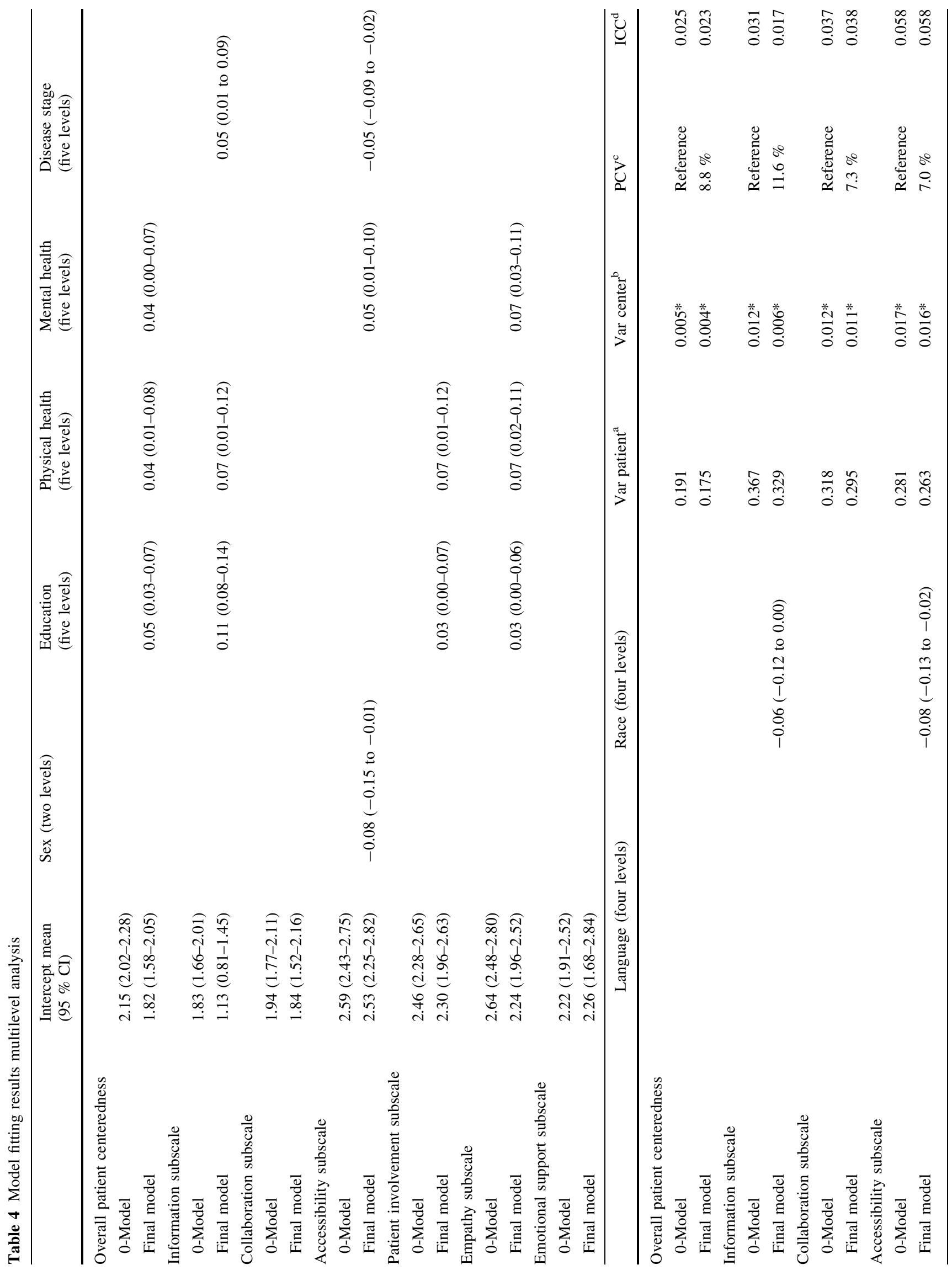




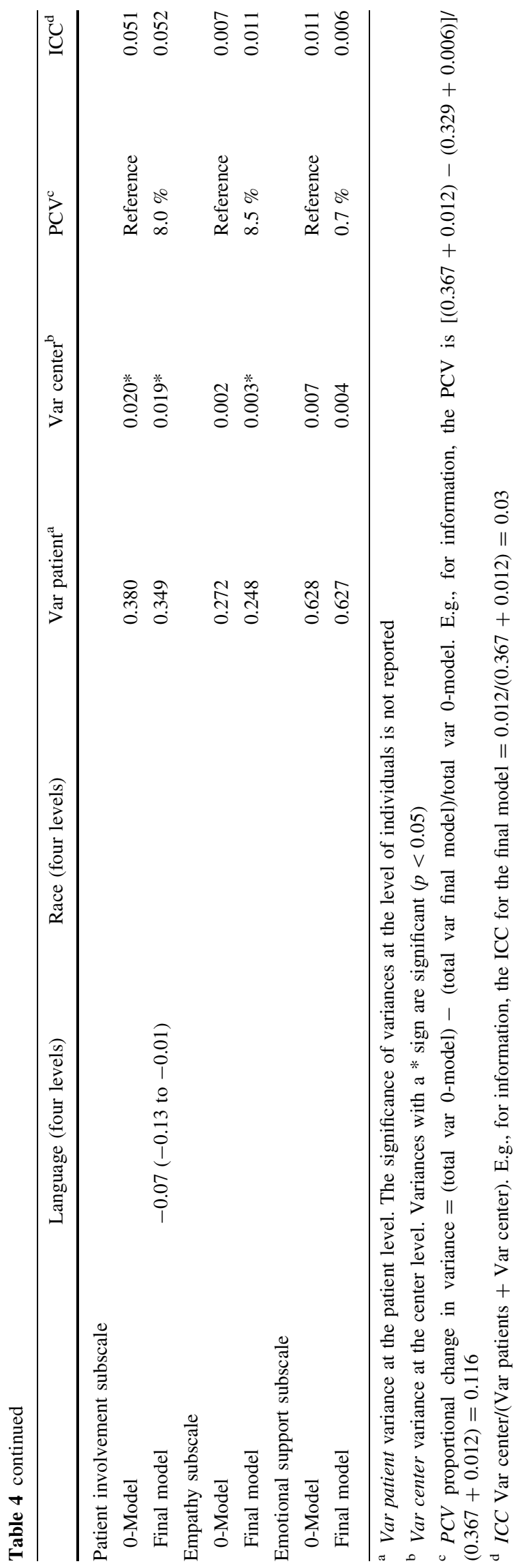

report within their medical team but did not know how to convert the feedback into a practicable action plan. Increasing the desire to change and improving the ability to translate feedback into an optimal improvement strategy are necessary future steps [33]. Furthermore, the content and timing of feedback are important [34]. Long-term conditions such as PD, require audits and feedback at regular intervals, provided to various levels of staff, in both verbal and written formats, and should include explicit targets to accomplish behavioral change [35].

This study uncovered significant differences in the level of patient centeredness between North American Parkinson centers. These differences may reflect meaningful variation; however, multilevel analysis revealed that differences between centers were accountable for only 1-6\% of the variance in patient centeredness. These values suggest that variation in experience scores occurred mainly at the patient level and to a lesser extent at the center level. Casemix adjustment did not change this result. Limited discriminative power is a common finding in experience surveys and may have resulted from the homogeneity of participating centers in our study [36]; all of these were established Centers of Excellence recognized by the American NPF. However, NPF centers do provide different services, resources, and professional disciplines on a center-by-center basis without standardization. Stratification for hospital factors might increase benchmark validity in future studies. Additionally, unknown confounders may have obliterated the variation between centers [36]. Limited discriminative power suggests that patients' experiences can be used for feedback and to rank the best and the worst performing centers but should not be utilized to list all centers in a consecutive order. If new payment models depend in part on care experiences, the discriminative power of experience surveys should be raised.

\section{Strengths}

First, cross-cultural validation contributed to the face and content validity of the PCQ-PD. We applied cognitive interviews to evaluate sources of response error in the questionnaire [19]. The PCQ-PD was developed based on the outcomes of eight focus group discussions in The Netherlands [30]. Some care aspects mentioned in these discussions were not found to be relevant for patients in the US, and it was necessary to rephrase some items. Overall, Dutch and North American patients showed similar values and needs.

Second, we applied casemix adjustment which is necessary for valid comparisons of care experiences across centers [22]. International studies confirm that patients' experiences differ significantly depending on age, education, and health status [24, 37, 38]. Researchers agree that 
the effect of casemix adjustment is modest, and patients' characteristics only predict a small percentage of the variability [36]. Nevertheless, when patients' experiences are used for benchmarking, hospital ranks are substantially affected by casemix adjustment [22].

\section{Shortcomings}

Our study was not without shortcomings. First, we included 27 patients suffering from atypical Parkinsonism, who may have dissimilar needs and may utilize different healthcare resources. However, these patients are part of the average patient population seen by NPF centers, and data analysis showed that their experiences did not deviate from patients with idiopathic PD. Additionally, NPF centers are more likely to routinely employ best practices in PD care and therefore most likely provide an overestimation of the level of patient centeredness when compared to general Parkinson care settings. Our patient mix analysis showed that participants were highly educated, English speaking, nonHispanic, Caucasian, and all covered by health insurance. These features do not completely reflect the US and Canadian population and may demonstrate inequitable access to high qualitative Parkinson care [39]. Future work also needs to study patient centeredness among these populations, and within centers that mainly serve these populations [40].

Second, patients were asked to self-rate their disease stage to facilitate the inclusion procedure. Normally, disease stage is classified by clinicians using the Hoehn and Yahr rating scale. We found that most medical records did not contain up-to-date disease stage ratings. Pragmatically, we therefore included self-reported medical data instead of performing actual physical examinations. This approach is not infallible, as some patients may find it hard to review whether the disease affects one or both sides of the body. Moreover, patients might complain about unilateral involvement, while the neurological evaluation shows bilateral involvement with regard to bradykinesia or rigidity. However, this inaccuracy was equally distributed among centers in our study. Ideally, future studies aimed at exploring care experiences should link these to up-to-date medical information stored within electronic health records.

\section{Future perspective}

The study provided a first step to increase awareness on patient-centered care in North-American Parkinson centers. Such findings create a basis for collecting patients' experiences in a repetitive fashion and intertwined with existing quality of care registries. This will allow for comparisons of the patient's perspective with the provided treatment, clinical outcomes, and costs. The data should become publicly available enabling direct comparisons across institutions and utilized to credit health professionals for providing patient-centered care.

Acknowledgments All patients who completed the PCQ-PD and members of the patient centeredness study group should be acknowledged for their participation. We acknowledge the National Parkinson Foundation for providing a research grant and the Parkinson centers at Nijmegen and Gainesville for anchoring the study. Anja van de Meulenreek is acknowledged for editing the manuscript for non-intellectual content. Jan Hendriks is acknowledged for his statistical advice.

Members of the patient centeredness study group

Aldred JL, MD (Gundersen Lutheran Neuroscience Center, La Crosse, WI, US, Medical director); Christine CW, MD (Department of Neurology, University of California UCSF, San Francisco, CA, US; Site Investigator); Bressman S, MD (Beth Israel Medical Center, New York, NY, US, Medical director); Browner N, MD (University of North Carolina UNC, Chapel Hill School of Medicine, NC, US, Medical director); Cho C, MD, MSCR (Department of Neurology, Mount Sinai School of Medicine, New York, NY, US, Medical director); Arney K, MSSW (Vanderbilt University Medical Center, Nashville, TN, US, Site Investigator); Biagioni MC, MD (NYU School of Medicine, Parkinson and Movement Disorder Division, Neurology Department, New York, NY, US, Site Investigator); Encarnacion EV, MD (Plummer Movement Disorders Center, Temple, TX, US, Medical director); Guttman M, MD, FRCPC (Center for Movement Disorders, Markham, Ontario, Canada, Medical director); Hobson DE, MD (Movement Disorder Clinic, Winnipeg, Manitoba, Canada, Medical director); Hung AY, MD, PhD (Department of Neurology, Massachusetts General Hospital, Boston, MA, US, Medical director);Jankovic J, MD (Department of Neurology, Parkinson's Disease Center and Movement Disorders Clinic, Baylor College of Medicine, Houston, TX, US, Medical director); Lafontaine AL, MD (Montreal Neurological Institute and Hospital, McGill Parkinson Program, Montreal, Quebec, Canada, Medical director); Mari Z, MD, MSCR (Johns Hopkins Parkinson's Disease \& Movement Disorders Center, Baltimore, MD, US, Medical director); Wieler M, BA, BScPT, MSc (Movement Disorders Program, Division of Neurology, University of Alberta, Edmonton, AB, Canada, Site Investigator); Morgan JC, MD, PhD (Movement and Cognitive Disorders Center, Department of Neurology, Medical College of Georgia, Georgia Regents University, Augusta, GA, US, Medical director); Nance MA, MD (Struthers Parkinson's Center, Golden Valley, MN, US, Medical director); Pagan FL, MD (Movement Disorders Program, Department of Neurology, Georgetown University Hospital, Washington, DC, US, Medical director); Book E, M.S.W., R.S.W (Pacific Parkinson's Research Center, University of British Columbia \& Vancouver Coastal Health, Vancouver, BC, Canada, Site Investigator).

\section{Compliance with ethical standards}

Conflicts of interest Martijn van der Eijk, MSc reports no disclosures. Marjan J. Faber, PhD reports no disclosures. Bart Post, MD, $\mathrm{PhD}$ reports no disclosures. Michael S. Okun, MD serves as a consultant for the National Parkinson Foundation and has received research grants from NIH, NPF, the Michael J. Fox Foundation, the Parkinson Alliance, Smallwood Foundation, the Bachmann-Strauss Foundation, the Tourette Syndrome Association, and the UF Foundation. Dr. Okun has previously received honoraria but in the past $>36$ months has received no support from industry. Dr. Okun has received royalties for publications with Demos, Manson, Amazon, and Cambridge (movement disorders books). Dr. Okun is an associate editor for New England Journal of Medicine and the Journal 
Watch Neurology. Dr. Okun has participated in CME activities on movement disorders in the last 36 months sponsored by PeerView, Prime, and by Vanderbilt University. The institution and not Dr. Okun receives grants from Medtronic and ANS/St. Jude, and the PI has no financial interest in these grants. Dr. Okun has participated as a site PI and/or co-I for several NIH, foundation, and industry-sponsored trials over the years but has not received honoraria. Peter Schmidt, $\mathrm{PhD}$ is the chief information officer and vice president of the NPF. Marten Munneke, PhD reports no disclosures. Prof Bastiaan R. Bloem has served as an editorial board member of Movement Disorders, currently serves as an editorial board member of Physiotherapy Canada, is Associate Editor for the Journal of Parkinson's disease, received honoraria from serving on the scientific advisory board for Danone, Glaxo-Smith-Kline, UCB and received research support from the Netherlands Organization for Scientific Research, the Michael J Fox Foundation, the Prinses Beatrix Foundation, National Parkinson Foundation, the Stichting Parkinson Fonds, and the Parkinson Vereniging.

Open Access This article is distributed under the terms of the Creative Commons Attribution 4.0 International License (http://crea tivecommons.org/licenses/by/4.0/), which permits unrestricted use, distribution, and reproduction in any medium, provided you give appropriate credit to the original author(s) and the source, provide a link to the Creative Commons license, and indicate if changes were made.

\section{References}

1. Corrigan JM, Donaldson MS, Kohn LT, Maguire SK, Pike KC (2001) Crossing the quality chasm. A new health system for the 21st century. National Academy of Medicine, National Academy Press, Washington DC

2. McMillan SS, Kendall E, Sav A et al (2013) Patient-centered approaches to health care: a systematic review of randomized controlled trials. Med Care Res Rev 70(6):567-596

3. Epstein RM, Fiscella K, Lesser CS, Stange KC (2010) Why the nation needs a policy push on patient-centered health care. Health Aff 29(8):1489-1495

4. Duggan PS, Geller G, Cooper LA, Beach MC (2006) The moral nature of patient centeredness: is it "just the right thing to do"? Patient Educ Couns 62(2):271-276

5. Meterko M, Wright S, Lin H, Lowy E, Cleary PD (2010) Mortality among patients with acute myocardial infarction: the influences of patient-centered care and evidence-based medicine. Health Serv Res 45(5Pt1):1188-1204

6. Michie S, Miles J, Weinman J (2003) Patient-centredness in chronic illness: what is it and does it matter? Patient Educ Couns 51(3):197-206

7. Patwardhan A, Patwardhan P (2009) Are consumer surveys valuable as a service improvement tool in health services? A critical appraisal. Int J Qual Health Care 22(7):670-685

8. Kahn KL, Schneider EC, Malin JL, Adams JL, Epstein AM (2007) Patient centered experiences in breast cancer: predicting long-term adherence to tamoxifen use. Med Care 45(5):431-439

9. Walsh T, Barr PJ, Thompson R et al (2014) Undetermined impact of patient decision support interventions on healthcare costs and savings: systematic review. BMJ 348:g188

10. Arterburn D, Wellman R, Westbrook E et al (2012) Introducing decision aids at Group Health was linked to sharply lower hip and knee surgery rates and costs. Health Aff 31(9):2094-2104
11. Bertakis KD, Azari R (2011) Patient-centered care is associated with decreased health care utilization. J Am Board Fam Med 24(3):229-239

12. Rathert C, Williams ES, McCaughey D, Ishqaidef G (2012) Patient perceptions of patient-centred care: empirical test of a theoretical model. Health Expect. doi:10.1111/hex.12020

13. Coulter A, Locock L, Ziebland S, Calabrese J (2014) Collecting data on patient experience is not enough: they must be used to improve care. BMJ 348:g2225

14. Dhanda J (2014) Treating patient experience and clinical outcomes equally. BMJ 348:g2714

15. Wensing M, Elwyn G (2003) Methods for incorporating patients' views in health care. BMJ 326(7394):877-879

16. Geissler KH, Friedberg MW, Steelfisher GK, Schneider EC (2013) Motivators and barriers to using patient experience reports for performance improvement. Med Care Res Rev 70(6):621-635

17. Elliott MN, Lehrman WG, Goldstein EH et al (2010) Hospital survey shows improvements in patient experience. Health Aff 29(11):2061-2067

18. van der Eijk M, Faber MJ, Ummels I, Aarts JW, Munneke M, Bloem BR (2012) Patient centeredness in PD care: development and validation of a patient experience questionnaire. Parkinsonism Relat Disord 18(9):1011-1016

19. Eremenco SL, Cella D, Arnold BJ (2005) A comprehensive method for the translation and cross-cultural validation of health status questionnaires. Eval Health Prof 28(2):212-232

20. Vierron E, Giraudeau B (2007) Sample size calculation for multicenter randomized trial: taking the center effect into account. Contemp Clin Trials 28(4):451-458

21. Fleiss JL (1999) The design and analysis of clinical experiments. Wiley Classics Library, New York

22. Holzer BM, Minder CE (2011) A simple approach to fairer hospital benchmarking using patient experience data. Int J Qual Health Care 23(5):524-530

23. Lyratzopoulos G, Elliott MN, Barbiere JM et al (2011) How can health care organizations be reliably compared?: lessons from a national survey of patient experience. Med Care 49(8):724-733

24. Damman OC, Stubbe JH, Hendriks M et al (2009) Using multilevel modeling to assess case-mix adjusters in consumer experience surveys in health care. Med Care 47(4):496-503

25. Merlo J, Yang M, Chaix B, Lynch J, Rastam L (2005) A brief conceptual tutorial on multilevel analysis in social epidemiology: investigating contextual phenomena in different groups of people. JECH 59(9):729-736

26. Buetow S, Giddings LS, Williams L, Nayar S (2008) Perceived unmet needs for health care among Parkinson's Society of New Zealand members with Parkinson's disease. Parkinsonism Relat Disord 14(6):495-500

27. Hayes C (2002) Identifying important issues for people with Parkinson's disease. Br J Nurs 11(2):91-97

28. Davis JT, Ehrhart A, Trzcinski BH, Kille S, Mount J (2003) Variability of experiences for individuals living with Parkinson's disease. JNPT 27(2):38-45

29. van der Eijk M, Faber MJ, Aarts JW, Kremer JA, Munneke M, Bloem BR (2013) Using online health communities to deliver patient-centered care to people with chronic conditions. J Med Internet Res 15(6):e115

30. van der Eijk M, Faber MJ, Al Shamma S, Munneke M, Bloem BR (2011) Moving towards patient-centered healthcare for patients with Parkinson's disease. Parkinsonism Relat Disord 17(5):360-364

31. Post B, van der Eijk M, Munneke M, Bloem BR (2011) Multidisciplinary care for Parkinson's disease: not if, but how! Pract Neurol 11(2):58-61

32. van der Marck MA, Munneke M, Mulleners W et al (2013) Integrated multidisciplinary care in Parkinson's disease: a non- 
randomised, controlled trial (IMPACT). Lancet Neurol 12(10):947-956

33. Reeves R, West E, Barron D (2013) Facilitated patient experience feedback can improve nursing care: a pilot study for a phase III cluster randomised controlled trial. BMC Health Serv Res 13:259

34. Geissler KH, Friedberg MW, SteelFisher GK, Schneider EC (2013) Motivators and barriers to using patient experience reports for performance improvement. Med Care Res Rev 70(6):621-635

35. Ivers N, Jamtvedt G, Flottorp S et al (2012) Audit and feedback: effects on professional practice and healthcare outcomes. Cochrane Database Syst Rev 6:CD000259

36. de Boer D, Delnoij D, Rademakers J (2011) The discriminative power of patient experience surveys. BMC Health Serv Res $11: 332$
37. Elliott MN, Swartz R, Adams J, Spritzer KL, Hays RD (2001) Casemix adjustment of the National CAHPS benchmarking data 1.0: a violation of model assumptions? Health Serv Res 36(3):555-573

38. Hargraves JL, Wilson IB, Zaslavsky A et al (2001) Adjusting for patient characteristics when analyzing reports from patients about hospital care. Med Care 39(6):635-641

39. Davis K, Ballreich J (2014) Equitable access to care-how the United States ranks internationally. N Engl J Med 371(17): $1567-1570$

40. The Lancet Neurology (2014) Consumer choices in Parkinson's disease. Lancet Neurol 13(6):525 